\title{
Understanding the definite integral with the help of Riemann sums
}

\author{
Özkan Ergene* \\ Department of Science and Mathematics Education, Sakarya University, Sakarya, Turkey \\ ORCID: 0000-0001-5119-2813
}

\author{
Ahmet Şükrü Özdemir \\ Department of Science and Mathematics Education, Marmara University, Istanbul, Turkey \\ ORCID: 0000-0002-0597-3093
}

\begin{tabular}{ll}
\hline \hline Article history & Students encounter difficulties in understanding integral because the \\
Received: & concept of integral requires the usage of theorems, formulas, daily life \\
& practices, and interdisciplinary approaches. From this point of view, in \\
Received in revised form: & this study we examine the effects of a teaching process consisting of \\
01.12 .2021 & modelling activities on understanding the definite integral with the help \\
& of Riemann sums. The research is designed according to the case study \\
Accepted: & based on a qualitative research method. Participants consist of 28 pre- \\
19.12 .2021 & service mathematics teachers who have limited understanding of integral \\
Key words: & although they have completed a Calculus course. The modelling activities \\
\hline definite integral, Riemann & were prepared in accordance with the emergent modelling approach. Data \\
sums, modelling activities, & were collected through integral test and semi-structured interviews \\
teaching process & conducted before and after the teaching process. Before the teaching \\
& process consisting of modelling activities, pre-service mathematics \\
& teachers' knowledge about the definite integral was included in the area \\
& under a curve, inverse of derivative and integral with known boundaries. \\
& In addition, participants did not refer to Riemann sums or cumulative \\
& sums. After the teaching process consisting of modelling activities, it was \\
& seen that almost all participants could explain the following equality \\
& ${ }_{n \rightarrow \infty} \sum_{k=1}^{n} f\left(c_{k}\right) \Delta x_{k}=\int_{a}^{b} f(x) d x$. At the end of the teaching process \\
& consisting of modelling activities, this process has enabled pre-service \\
& teachers to establish the relationship between Riemann sum and definite \\
& integral. Findings revealed that teaching process of the definite integral \\
& enhanced the understanding the definite integral.
\end{tabular}

\section{Introduction}

The concept of integral is inherently closely related to the concepts of series, limit and derivative and it is used as an umbrella concept in conjunction with many subjects or situations such as functions, trigonometry, geometry, and real-life problems. Many researchers have accepted the challenges of teaching and learning of integral which is an important concept in Calculus (Ergene, 2014; Ferrini-Mundy \& Graham, 1994; Rasslan \& Tall, 2002). Students generally regard integral as an area under a curve or inverse of derivative and this causes limited understanding of the integral (Sealey, 2008). This limited

\footnotetext{
*Correspondency: ozkanergene@sakarya.edu.tr, ozkanergene@gmail.com
} 
understanding causes not to notice the theoretical structure underlying integral concept. For example, a student who can successfully solve the integral problem $\int_{a}^{b} e^{x} d x$ and find the answer $\left(e^{b}-e^{a}\right)$ gives a response as the definite integral [DI] or inverse of derivative to the question "What does $\int_{a}^{b} f(x) d x$ mean?". This response shows limited and incomplete understanding of integral. Furthermore, limited understanding of integral leads students to see integral as an abstract and difficult concept and also to have high anxiety and negative attitude towards the concept of integral (Ergene, 2021a, Ergene, 2019; Ergene \& Özdemir, 2020a).

Nowadays in mathematics education, using of technology, modelling activities, and real-life problems are offered in order to develop understanding of mathematical concepts. For the understanding of integral, it is suggested that the key concepts such as Riemann sums [RS] and Fundamental Theorem of Calculus [FTC] should be emphasized in teaching process of integral. Furthermore, consideration that integral is a concept that is not far from real-life will be appropriate to the purpose of today's education system.

In this paper, firstly, the problem is defined and explained by supporting with the literature. After that, significance of the study is expressed and finally, the teaching process as a possible remedy for the problem is presented

\section{Defining the Problem}

The first researcher of the present study has noticed some problems in the teaching process of integral in calculus courses which he has taken before. In these courses, instructors did not pay attention to RS and real-life applications of integral and they taught integral by providing formula or sequence of operations. Furthermore, it was observed that students who successfully completed the courses in which the integral is taught, used only procedural or formula-based stereotypes related to the integral. This situation experienced by the researcher takes place also in the related literature.

\section{Literature Review}

In line with the focus of this research, in this section the concept of DI is emphasized. Studies on the concept of DI are about the lack of understanding of DI, difficulties in the use of RS and incomplete or incorrect use of DI in different disciplines and real-life situations.

Research indicated that although most of the students were able to apply routine step-by-step basic integral procedures to find the area under a curve, they were rarely able to explain their operations (Artigue, 1991). In addition, Chapell and Kilpatrick (2003) found that students who have experienced concept-based instruction scored significantly higher than students who have received process-based instruction. Hence, it is suggested that concept-based teaching can help students enhance their understanding in calculus courses (Mahir, 2009). Understanding of DI can be enhanced by using the following basic behaviors.

- DI can be defined by emphasising "FTC", "area under a curve" and "cumulative sums".

- Using of DI in real-life situations (Berry \& Nyman, 2003; Thompson, 1994) 
Cumulative sums emphasis. Computation of DI can be made by using limit of RS if DI exists and the function is continuous $\left(\int_{a}^{b} f(x) d x=\lim _{n \rightarrow \infty} \sum_{i=1}^{n} f\left(x_{i}\right) . \Delta x_{i}\right)$ (Shekutkovski, 2013). Hence, the concept of limit is important in making sense of RS. RS is commonly used in the partitioning process and are often preferred in mathematics (Thomas, Weir, Hass \& Giordano, 2016). However, research showed that most of the students had difficulty in calculating given RS (Orton, 1983) and they were reluctant to understand why RS and integral are used (Wagner, 2018). It was also observed that difficulties in teaching concept of integral can be stem form instructors' way of teaching. For instance, Jones (2015a) emphasised that teachers did not spend enough time on RS while teaching DI.

On the other hand, Darvishzadeh, Shahvarani-Semnani, Alamolhodaei and Behzadi (2018) found that the use of RS while of solving the integral problem increases achievement. Moreover, calculating desired distance by multiplying quantities such as time and speed is important to understand RS conceptually (Jones, Lim \& Chandler, 2017). In addition to graphical only interpretations, emphasising cumulative sum concept can support development of students' quantitative reasoning (Jones, 2018).

RS and Area under a Curve. According to Nguyen and Rebello (2011) and Rasslan and Tall (2002), students' knowledge about integral is limited to the area under a curve. Although students could perform routine procedures to calculate area under a curve, they rarely could explain underlying reason behind their calculations (Artigue, 1991). Since they were unable to associate this area with RS, they lacked conceptional understanding (Sealey, 2008). Students believe that use of RS in calculating the area of small rectangles under a curve is just a proof and that its relationship with DI is not strong (Ferrini-Mundi \& Graham, 1994). Therefore, association of DI with the area under a curve is much more dominant and common among students than RS.

McDermott, Rosenquist and van Zee (1987) stated that in physics problems, students demonstrate operational skills to find the area under a curve, but they did not possess the knowledge regarding why the area under a curve is equal to the work or total energy. In interpreting the area under a curve with the function graph, it is emphasized that the structure of RS should be understood in order to understand that the area can also express a different situation, such as speed, work or energy (Thompson \& Silverman, 2007). One of the main reasons for the use of integral in this way might be that RS are not emphasized and integral concept is explained away from the real-life.

\section{Significance of the Study}

Students might not hold quantitative meanings for the components of an integral despite being proficient with integral calculations (Orton, 1983; Orton, 1984; Serhan, 2015; Rasslan \& Tall, 2002); challenges students experience when attempting to apply definite integrals to contexts in physics or engineering (Sealey, 2014; Meredith \& Marrongellle, 2008; Simmons \& Oehrtman, 2017; Chhetri \& Oehrtman, 2015); students' difficulties with coordinating the product structure of an accumulated quantity (Sealey, 2014); components of productive understandings of the Fundamental Theorem of Calculus and the product structure of integral applications in the sciences (Carlson, Smith, \& Persson, 2003; Thompson, 1994); the productivity of understanding the integral as a "quantitative-based summation" in modelling (Chhetri \& Oehrtman, 2015; Simmons \& Oehrtman, 2017). Broadly, these studies highlight that a constructive understanding of integration involves attention to the products generating the accumulated quantity. Therefore, while teaching the concept of RS and DI, we 
should take students' difficulties into account and provide them opportunities to engage in activities that help them understand these concepts (Sealey, 2014). Moreover, in studies that provide solutions to the difficulties experienced in the understanding of integral, the necessity of using real-life problems involving RS in different contexts is emphasized. As Sealey (2014) stated that additional research on students' understanding of RS and DI and how they set up a definite integral in the form of $\int_{a}^{b} f(x) d x$ is required. Thus, it is believed that this study may contribute to the literature by revealing how they establish a connection between RS and DI. In this research, the Teaching Process of the Definite Integral [TPD] was designed by using modelling activities that can enhance the understanding of DI with the help of RS.

The purpose of this research is to examine how TPD affects understanding of DI with the help of RS. In the present study, understanding of DI includes "DI knowledge", "association of DI with the use of RS" and "association of DI with the concepts of limit and derivative". For this purpose, answers to the following questions were sought:

(1)How did the understanding of DI change after TPD?

(2)How did TPD support establishment of the relationship between DI and limit-derivative concepts?

\section{Research Design}

In this study, qualitative research method (Creswell, 2003) was used. With the research purpose, since understanding of DI included "DI knowledge", "association of DI with the use of RS" and "association of DI with the concepts of limit and derivative", embedded single case study design (Yin, 2003) was adopted. Thus, cases were addressed in all aspects and in-depth perspective in the present study (Cohen, Manion \& Morrison, 2000).

\section{Participants}

The participants of the study consist of 28 pre-service teachers who were enrolled in Elementary Mathematics Education Program of Faculty of Education in one of the state universities in Turkey. They were senior students and taking an elective course at the time of the study. They chose this course among elective course options. The instructor of the course was the first author of this study. The researcher mentioned the purpose and requirements of the study to pre-service teachers. It was explained to pre-service teachers that participating in the study requires solving some problems, taking some tests, and making interviews with the researcher without affecting their grade point average in that course. For the study, 28 preservice teachers were selected on voluntarily basis. The study was conducted with them out of the class hours. In order to ensure confidentiality, pre-service teachers were named as $\mathrm{P}_{1}$, $\mathrm{P}_{2}, \ldots \mathrm{P}_{28}$ in the following sections. The reason for selecting these participants is the fact that although the pre-service teachers have completed the courses in which integral is taught, they demonstrated procedural skills regarding integral. Pre-service teachers have learned the concept of integral in Calculus II course 5 semesters before the present study was conducted. They were completed this course with - different grades.

\section{Conceptual framework and Teaching Process of the Definite Integral}

TPD which consists of modelling activities based on "development of partition idea", "use of RS" and "use of DI" was designed in order to enhance understanding of DI. The modelling activities in TPD were designed according to the emergent modelling approach (Gravemeijer, 2007). In emergent modelling approach, students can develop formal 
mathematical knowledge based on their informal knowledge by engaging in mathematical activities including contextual tasks (Gravemeijer \& Stephan, 2002). Students begin with a "model of" a context which is familiar to them and move towards "model for" by solving problems in various contexts. In this way, students' informal thinking shifts towards formal mathematical reasoning eventually (Gravemeijer, 1999). In emergent modelling approach, activities and teaching process should be carried out for a long period of time (Gravemeijer, 2007). In this study 8 different modelling activities were used in TPD which lasted approximately 6 weeks. While the first six modelling activities $\left(A_{1}-A_{6}\right)$ were designed to develop the understanding of DI, the last two modelling activities were designed to evaluate $\mathrm{A}_{1}-\mathrm{A}_{6}$. In addition, the activity "areas of shapes" was implemented before the activity $\mathrm{A}_{1}$ (Motorized Courier) in the classroom. "Area under a curve" activity was given to the participants as a homework. The flow of the teaching process including modelling activities is presented in Figure 1.

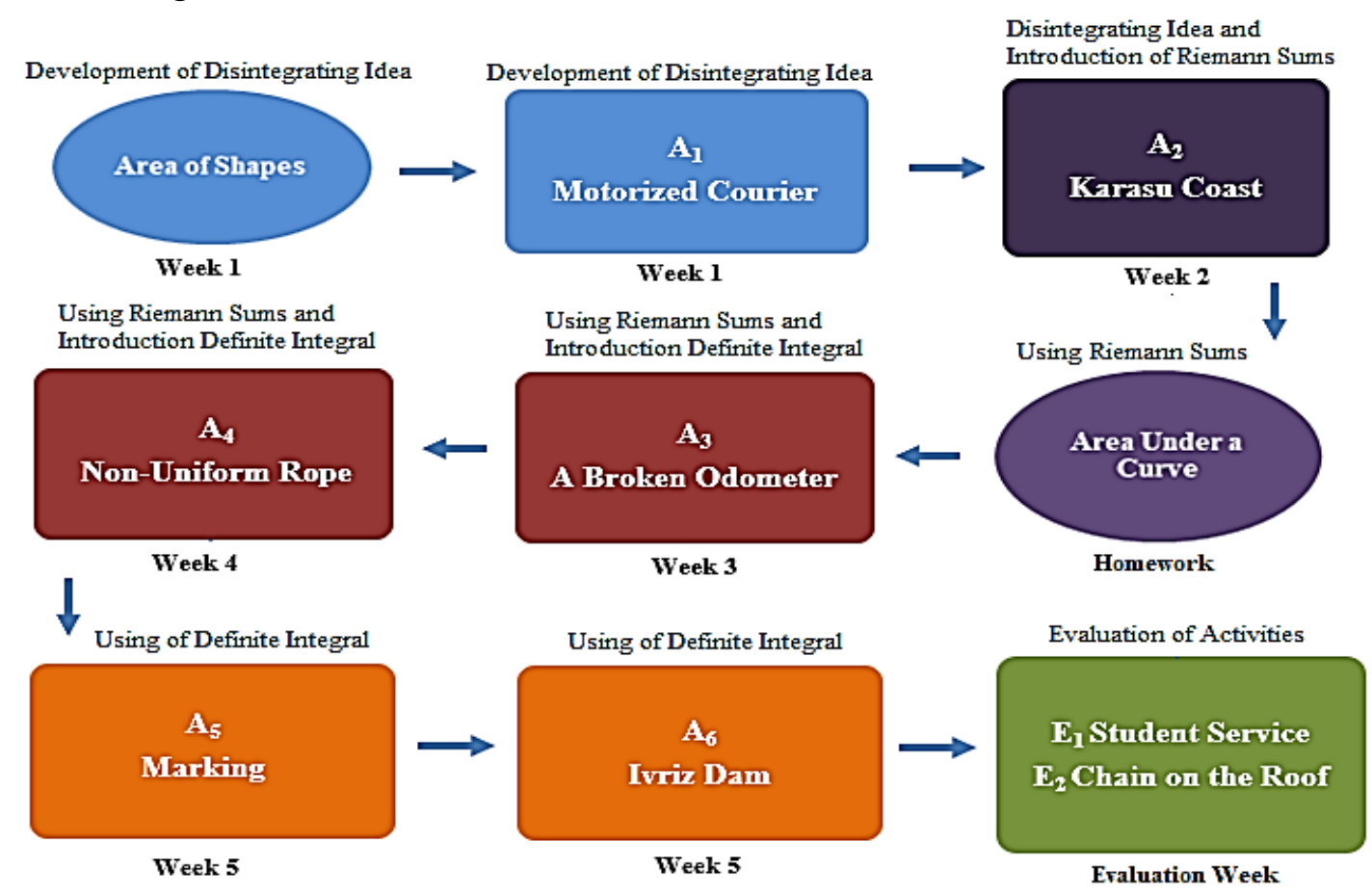

Figure 1. The flow of the teaching process including modelling activities

The modelling activities used in the teaching process were determined in line with the aim of the study. For instance, $A_{1}$, Motorized Courier was taken from Thompson's (1994) study and modified by the researchers for the purpose of the study, i.e., in order to examine the development of the partition idea. In his study, Thompson asked a young student of him the following problem: "Imagine this. I'm driving my car at $50 \mathrm{mi} / \mathrm{hr}$. I speed up smoothly to 60 $\mathrm{mi} / \mathrm{hr}$, and it takes me one hour to do it. About how far did I go in that hour?" Thompson's student expressed that the distance can be found with better approaches by using smaller time intervals in roughly calculation of a distance that can be travelled. This problem was modified by the researchers with an aim to identify the relation between the road proceeded by the courier carrying cargo between two cities, and the time by using partition idea. The other modelling activities used in the teaching process were designed in a similar way by ensuring their validity and reliability (see Appendix for some of the modelling activities).

Pilot study of the TPD was conducted with three pre-service teachers. In teaching process, 
firstly development of partition idea and then, use of RS and finally conception of the definite integral and the relationship between DI and RS were aimed. During the TPD, while participants were engaging in modelling activities, the researcher guided them by using questioning and brainstorming methods to help them make sense of DI because students cannot discover all mathematical concepts themselves but through guided reinvention (Doorman \& Gravemeijer, 2009). Detailed information about the TPD was given in Appendix. The TPD was implemented in individual, and group works in weekly meetings in the class.

\section{Data Collection Tools}

Data were collected through the integral test and semi-structured interviews in the study. The integral test was used to identify participants' knowledge about DI and to examine the effect of the TPD. The semi-structured interviews were conducted to determine the participants' views about DI and to determine differences in their opinions before and after the TPD.

Triangulation technique was used in this research with the idea that it would increase the internal validity and reliability of the study (Creswell, 2003). For example, the use of the integral test and semi-structured interviews as different data collection tools indicates that this study was performed by using triangulation to improve the validity and reliability (Yin, 2003).

\section{Integral Test}

The integral test was developed by the researchers and consisted of 5 open-ended questions. It was implemented before and after the TPD in order to identify participants' knowledge about DI. In the integral test, $1^{\text {st }}$ question was about symbolic meaning of DI, $2^{\text {nd }}$ question was about the relationship between DI and the concepts of limit and derivative, $3^{\text {rd }}$ question was about the ordering of use of DI in the integral teaching process, $4^{\text {th }}$ question was about calculations and interpreting given functions and $5^{\text {th }}$ question was about associating DI with the function graph.

In the first phase, the questions were presented to three experts who have a $\mathrm{PhD}$ degree in mathematics education. After the questions were revised according to expert opinions, a pilot study was conducted with 34 participants. After the pilot study, some revisions were made in the questions and the integral test was ready to administer for the main study. The integral test was administered to the participants at the beginning and at the end of the TPD as a pre-test and post-test respectively.

\section{Semi-Structured Interview}

In the semi-structured interview protocol, there were 2 questions. $1^{\text {st }}$ question was "What does a DI mean?" and $2^{\text {nd }}$ question was "Can you explain $\left.\int_{a}^{b} f(x) d x=\lim _{n \rightarrow \infty} \sum_{i=1}^{n} f\left(x_{i}\right) \cdot \Delta x_{i}\right)$ ?". Semi-structured interviews were conducted with the participants at the beginning and at the end of the TPD as a pre-interview and postinterview respectively.

\section{Data Collection Process}

During the data collection process, firstly, the pre-integral test was administered to, and pre-interviews were conducted with the participants in order to determine their 
knowledge about integral. Then, the TPD was implemented in weekly periods but only "Marking" and "Ivriz Dam" activities were implemented in the $5^{\text {th }}$ week but in different days. One-week break was given for the evaluation of activities "Student Service" and "Roof Chain". At the end of the TPD, the post-integral test was administered after four-weeks break after the implementation of the evaluation activities in order to ensure retention and then postinterviews were conducted with the participants.

\section{Data Analysis}

The data obtained from the semi-structured interviews were transcribed as verbatim. Findings from the transcripts were presented in various sections with direct quotations. Codes and categories were created from the participants' responses to the questions in the Integral Test. The participants' responses for $1^{\text {st }}$ and $2^{\text {nd }}$ questions in the integral test and $1^{\text {st }}$ question in the semi structured interview were coded by using analytical-inductive method (Knuth, 2002). First, the external (researcher-generated) codes were determined before data analysis. Related literature, expert opinions and the researchers' point of view have been effective in the process of creating the categories. While analysing the data, other categories emerged as internal (data-grounded) codes. For instance, for the $1^{\text {st }}$ question in the integral test, "area under a curve", "inverse of derivative/FTC" and "cumulative sums" codes were ascertained as external codes. In addition to these codes, during data analysis "definite integral" code emerged and was added as an internal code. Moreover, for the $1^{\text {st }}$ question asked in the interviews, while "area under a curve" and "cumulative sums" were identified as external codes, "integral with known boundaries" emerged as an internal code. On the other hand, $4^{\text {th }}$ question in the integral test and $2^{\text {nd }}$ question in the interviews were analysed through a rubric. Categories, code samples, and examples for the participants' solutions are presented in tables in the findings section.

\section{Findings}

The findings of the study will be presented in two sections consisting of findings related to the integral test and findings related to the semi-structured interviews.

\section{Findings for Integral test}

Responses given by the participants to the questions "What does the representation of $\int_{a}^{b} f(x) d x$ means to you?" were examined in four categories which are DI, area under a curve, inverse of derivative/FTC, and cumulative sums. These categories, related codes and examples for the participants' responses are presented in Table 1.

Table 1. Categories, codes and examples for the $1^{\text {st }}$ question in the integral test

\begin{tabular}{lll}
\hline Category & Code & Example for participants' responses \\
\hline Area under a curve & $\begin{array}{l}\text { Area of Region } \\
\text { Function }\end{array}$ & The area of $f(x)$ function between a and $\mathrm{b}$. \\
$\begin{array}{l}\text { Inverse of } \\
\text { derivative/ FTC }\end{array}$ & $\begin{array}{l}\text { Anti-derivative } \\
\text { FTC }\end{array}$ & The inverse of derivative \\
Cumulative Sums & $\begin{array}{l}\text { RS } \\
\text { DI }\end{array}$ & $\begin{array}{l}\text { The sum of the changes } \\
\text { DI from } a \text { to } b\end{array}$ \\
& DI depending on function & $\begin{array}{l}\int_{a}^{b} f(x) d x \text { representation is the integral of } f(x) \text { function } \\
\text { from } a \text { to } b . \text { This integral is a definite integral. }\end{array}$ \\
\hline
\end{tabular}

Frequencies of the participants for the $1^{\text {st }}$ question in the pre- and post-integral test are given in Table 2. In the pre-integral test, it was observed that most of the participants $(n=23)$ said 
area under a curve for $\int_{a}^{b} f(x) d x$ representation. In the post-integral test, 26 of the participants associated this representation with the area under a curve, 17 of them associated it with inverse of derivative/FTC and 19 associated it with the cumulative sums.

Table 2. Frequencies of the participants for the $1^{\text {st }}$ question in pre- and post-integral test

\begin{tabular}{lll}
\hline Category & Pre-IT (f) & Post-IT (f) \\
\hline Area under a curve & 23 & 26 \\
Inverse of derivative/FTC & 9 & 17 \\
Cumulative sums & 1 & 19 \\
DI & 4 & 5 \\
\hline
\end{tabular}

When the participants' responses were examined, it was seen that there is a remarkable change in the cumulative sums category. In addition, for all categories, there was an increase in the number of participants in the post integral test. Figure 2 shows one of the participants', $\mathrm{P}_{23}$, response to the 1 st question in the pre- and post-integral test.

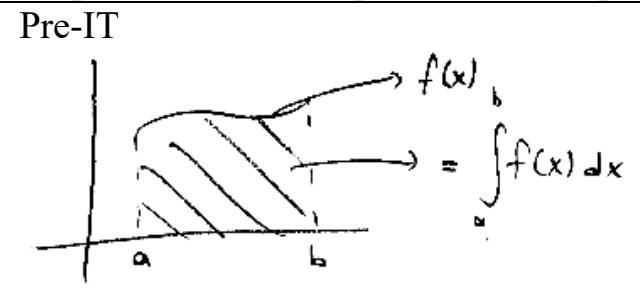

The area of a function $f(x)$ between a and $b$

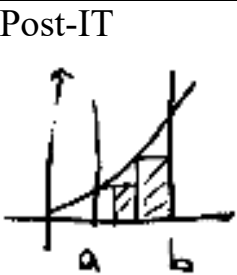

Area of a region from a to $b$

The cumulative sum of very small pieces in the

$$
\begin{aligned}
& \text { region from } \quad a \quad \text { to } \quad b \\
& \int_{a}^{b} f(x) d x=\lim \sum_{i=1}^{n} f\left(x_{i}\right) \Delta x_{i}=F(b)-F(a)
\end{aligned}
$$

Figure 2. The responses of $\mathrm{P}_{23}$ to the $1^{\text {st }}$ question in the pre- and post-integral test

For the question "Is the definite integral related to limit and derivative? Explain your response with reasons." codes and categories were identified, and 24 codes have been created in total. 12 codes which contain DI and limit relationship were combined into 4 categories and 12 codes containing DI and derivative relationship were combined into 6 categories as shown in Table 3.

Table 3. Categories, examples of codes, and descriptions for the $2^{\text {nd }}$ question in the integral test

\begin{tabular}{lll}
\hline Category & Examples of Codes \\
\hline RS & While expressing with RS, limit is used. \\
The limit is used in the calculations of the lower sum and the upper sum \\
Indirect & There is a cyclical relationship between limit, derivative and integral. Derivative and \\
Relationship & limit constitute the basis for integral. \\
Not Related & No relationship. \\
Other & Have no idea or unrelated explanation \\
\hline & FTC & FTC \\
\hline Inverse of & Integral is inverse of derivative \\
derivative & Derivative is used when calculating the amount of change \\
Change & Derivative affects integral. \\
Indirect & No relationship. \\
Rotionship & No explanation or unrelated explanation \\
Other &
\end{tabular}


The distribution of the expressions of participants to explain the relationship between DI and limit is given in Table 4. In the pre-integral test, it was observed that the participants generally expressed an indirect relationship between DI and limit. In the post-integral test, it was observed that the participants except $\mathrm{P}_{9}, \mathrm{P}_{20}, \mathrm{P}_{22}$ and $\mathrm{P}_{27}$ explained the relationship between DI and limit by referring to RS.

Table 4. Frequencies of the participants in pre- and post-integral test for DI-limit relationship

\section{Category}

RS

Indirect Relationship

No relations

Other

\begin{tabular}{ll} 
Pre-IT (f) & Post-IT (f) \\
3 & 24 \\
12 & 2 \\
1 & - \\
12 & 2 \\
\hline
\end{tabular}

The frequencies of the participants explaining the relationship between DI and derivative is given in Table 5. In the pre-integral test, most of the participants who explained the relationship between DI and derivative stated that integral is the inverse of derivative. In the post-integral test, 13 participants explained the relationship between DI and derivative by referring to FTC.

Table 5. Frequencies of the participants in the pre- and post-integral test for DI-derivative relationship

\begin{tabular}{lll}
\hline Category & Pre-IT (f) & Post-IT (f) \\
\hline FTC & 2 & 13 \\
Inverse of derivative & 12 & 12 \\
Rate of Change & 0 & 1 \\
Indirect Relationship & 3 & 1 \\
No relations & 1 & 0 \\
Other & 10 & 3 \\
\hline
\end{tabular}

Some participants used FTC and RS simultaneously while explaining the relationship between DI and the concepts of limit and derivative as it is shown below:

DI is associated with limit and derivative. If we explain this relationship mathematically:

(1)FTC $=\int_{a}^{b} f(x) d x=F(b)-F(a)$

(2) $\int_{a}^{b} f(x) d x=\lim _{n \rightarrow \infty} \sum_{i=1}^{n} f\left(x_{i}\right) \Delta x_{i}$

The responses of the participants to the $3^{\text {rd }}$ question in the integral test showed a remarkable finding. The participants $(\mathrm{n}=25)$, except $\mathrm{P}_{1}, \mathrm{P}_{2}$ and $\mathrm{P}_{26}$, said that "Integral instruction should start with indefinite integral and then DI" in the pre-integral test. The participants who considered the necessity of starting with indefinite integral emphasized that integral must be learned with their rules and formulas at first. The participants, except $\mathrm{P}_{6}, \mathrm{P}_{8}$ and $\mathrm{P}_{20},(\mathrm{n}=25)$ said that "Integral instruction should be start with DI and then continue with indefinite integral" in the post-integral test. The participants who considered the necessity of starting with DI stated that "firstly the purpose of the integral should be taught, and the meaning of integral should be explained". In the post-integral test, $\mathrm{P}_{1}$ stated that he did not understand area-volume calculation-oriented problems in the high school and that integral teaching should be start with DI as it is given below. 
When I think about my high school education, I come to realize that I didn't understand anything about the volume and area calculation problems related to integral and I couldn't solve them. Now, I know that there's a reason behind it. I think it's more appropriate to teach DI first, and then indefinite integral.

In the $4^{\text {th }}$ question regarding the calculation of $\int_{a}^{b} e^{x} d x, \int_{a}^{b} e^{\frac{x}{3}} d x, \int_{a}^{b} e^{\sqrt{x}} d x, \int_{a}^{b} e^{x^{2}} d x$ integrals in IT, the answers of participants were evaluated as correct [C], partially correct $[\mathrm{PC}]$, incorrect $[\mathrm{IC}]$ and no response $[\mathrm{NR}]$ as represented in Table 6 below.

Table 6. Frequencies of the participants for the $4^{\text {th }}$ question in the pre- and post-integral test

\begin{tabular}{lcccccccc}
\hline & $\int_{a}^{b} e^{x} d x$ & \multicolumn{2}{c}{$\int_{a}^{b} e^{\frac{x}{3}} d x$} & $\int_{a}^{b} e^{\sqrt{x}} d x$ & \multicolumn{2}{c}{$\int_{a}^{b} e^{x^{2}} d x$} \\
\hline & Pre-test & Post-test & Pre-test & Post-test & Pre-test & Post-test & Pre-test & Post-test \\
\hline C & 28 & 28 & 25 & 28 & 9 & 11 & 0 & 11 \\
PC & 0 & 0 & 0 & 0 & 7 & 5 & 2 & 6 \\
IC & 0 & 0 & 3 & 0 & 6 & 5 & 11 & 5 \\
NR & 0 & 0 & 0 & 0 & 6 & 7 & 15 & 6 \\
\hline
\end{tabular}

All participants calculated the integral $\int_{a}^{b} e^{x} d x$ correctly in the pre- and post-integral test. In the pre integral test, only three participants calculated the integral $\int_{a}^{b} e^{\frac{x}{3}} d x$ incorrectly while in the post integral test, all participants calculated correctly.

While there were no participants who correctly calculated the integral $\int_{a}^{b} e^{x^{2}} d x$, only two participants calculated it partially correctly in the pre-integral test. In the post-integral test, a remarkable difference emerged, and 11 participants calculated correctly, and 6 participants calculated partially correctly. There has also been a significant decrease in the number of participants who calculated incorrectly and those who gave no response in the post integral test. In addition, participants who tried to solve the problems by using algebraic methods $\left(\int_{a}^{b} e^{x} d x=e^{x} \mathrm{I}_{a}^{b}=e^{b}-e^{a}\right)$ in the pre integral test stated that given integrals correspond to the areas under the curves in the post integral test. For instance, $\mathrm{P}_{14}$ wrote: "It can be found by drawing graphs of all of them and calculating what falls under a curve in the $(a, b)$ range. If we know how to draw the graph of function $e^{x}$ and if $(a, b)$ are given to us, we can calculate the area without using a formula."

In the $5^{\text {th }}$ question in the integral test, the participants were given a graph of a $f(x)$ function located in the coordinate axis and asked "How can you calculate the area between the graph of $f(x)$ function and the x-axis? Explain your response in detail." In the pre integral test, all participants algebraically expressed area of a given region either in the form of $\int_{a}^{b} f(x) d x$ or in the form of $\int_{a}^{c} f(x) d x+\int_{c}^{b} f(x) d x$. In the pre integral test, none of the participants used RS or cumulative sums. Figure 3 shows the response given by a participant to the $5^{\text {th }}$ question. 


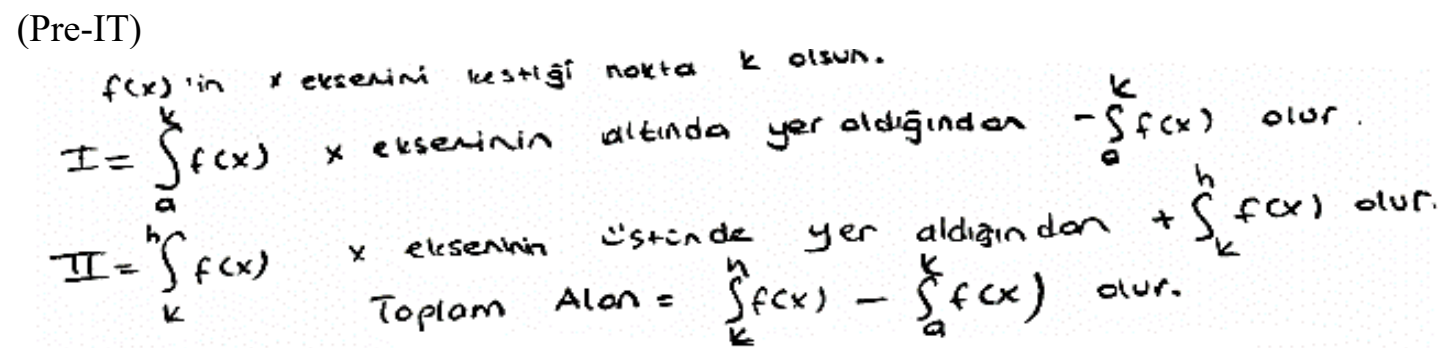

The point at which $f(x)$ cuts the $x$ axis is $k$.

$\mathrm{I}=\int_{a}^{k} f(x)$ is located below the $\mathrm{x}$ axis, it becomes $-\int_{\mathrm{a}}^{\mathrm{k}} f(x)$.

Because II $=\int_{\mathrm{k}}^{\mathrm{h}} f(x)$ is located above the $\mathrm{x}$ axis, it becomes $+\int_{k}^{h} f(x)$ Total Area is $\int_{k}^{h} f(x)-$ $\int_{a}^{k} f(x)$

(Post-IT)

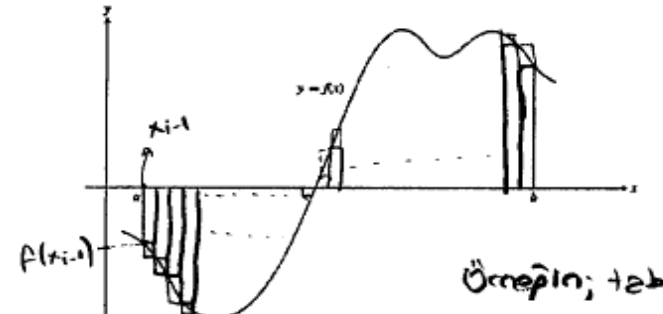

Oncolitle $\int_{e}^{n} f(x) d x$ isleniyle heseplarbilir.
Bunn disinde bu prefipin altinde kalen bolpeyi,

alonin, heseplayebileopimiz adjentere agirablinit

Örnepin; tabonler esit olen sonsur seylde ditabrtgene.

$\Delta x=\frac{b \cdot a}{n} \lim _{n \rightarrow \infty} \sum_{i=1}^{n} f\left(x_{i-1}\right) \cdot \Delta x=\lim _{n \rightarrow \infty} \sum_{i=1}^{n} f\left(x_{i}\right) \cdot \Delta x=\int_{0}^{n} f(x) d x$

Firstly, it can be calculated with $\int_{a}^{k} f(x) d x$. Also, we can divide the area below this graph into polygons and we can calculate the area. For example, an infinite number of rectangles with equal bases.

$$
\Delta x=\frac{b-a}{n}, \underset{n \rightarrow \infty}{\lim } \sum_{i=1}^{n} f\left(x_{i-1}\right) \Delta x=\lim _{n \rightarrow \infty} \sum_{i=1}^{n} f\left(x_{i}\right) \Delta x=\int_{a}^{b} f(x) d x
$$

Figure 3. An example for the participants' responses to the $5^{\text {th }}$ question

In the post-integral test, all participants stated that the area can be divided into very small pieces in the form of rectangles to find the area of the specified region, as well as calculating the area with the help of RS.

\section{Findings for Semi-Structured Interviews}

The responses of the participants to the $1^{\text {st }}$ question in the interview were categorized as area under a curve, an integral with known boundaries and cumulative sums. Frequencies of the participants for the $1^{\text {st }}$ question in the interview are presented in Table 7.

Table 7. Frequencies of the participants for the $1^{\text {st }}$ question in the interviews

\begin{tabular}{lll}
\hline & Pre-interview (f) & Post-interview (f) \\
\hline Area under a curve & 24 & 27 \\
An integral with known boundaries & 13 & 4 \\
Cumulative sums & 2 & 27 \\
\hline
\end{tabular}


In the pre-interview, most of the participants $(n=24)$ responded to the question "What is a DI?" as the area under a curve. Moreover, some participants $(n=13)$ also said an integral which has known boundaries. On the other hand, in the post-interview, almost all participants indicated DI as area under a curve $(n=27)$ and cumulative sums $(n=27)$. For instance, while $\mathrm{P}_{23}$ stated that DI is area under a curve in the pre-interview, she could associate DI with RS in the post-interview as shown in below. In addition, the participants $\mathrm{P}_{7}, \mathrm{P}_{17}, \mathrm{P}_{18}, \mathrm{P}_{27}$ explained DI as "integral with known boundaries".

\section{R: What does DI mean?}

$P_{23}$ : Think about an axis. It could be the coordinate axis. Let's think about the curve of an $f(x)$ function on the $x$-axis on the coordinate axis. Let's make a boundary for? the remaining region between the curve of this $f(x)$ function and the $x$-axis in the [a,b] range. We can use DI whenever we want to calculate the area of this region... In order to calculate the area of a region I just mentioned, we can divide the area into very small rectangular pieces. We can calculate the area of the entire region through the areas of the rectangles. This is also used in DI, but the logic is different. The more we increase the number of rectangles, the closer we can get to the actual value of the area. We can minimize the difference between the lower sums and the upper sums. This means Riemann sums...

The participants' responses to the $2^{\text {nd }}$ question were evaluated as no response, partly to be informed, identified with RS. In the pre-interview, it was observed that great majority of the participants $(\mathrm{n}=20)$ did not know $\int_{a}^{b} f(x) d x=\lim _{n \rightarrow \infty} \sum_{i=1}^{n} f\left(x_{i}\right) . \Delta x_{i}$. In addition, 8 participants $\left(\mathrm{P}_{1}, \mathrm{P}_{2}, \mathrm{P}_{8}, \mathrm{P}_{19}, \mathrm{P}_{21}, \mathrm{P}_{24}, \mathrm{P}_{25}, \mathrm{P}_{28}\right)$ mentioned such as "the lower sum, the upper sum or may be related to the RS". Following excerpt illustrates this situation.

$R:$ Can you explain the expression $\int_{a}^{b} f(x) d x=\lim _{n \rightarrow \infty} \sum_{i=1}^{n} f\left(x_{i}\right) \cdot \Delta x_{i}$ ?

$P_{17}:$ Hmm, there's something about integral and the sigma notation.

$R$ : What do you think when you see this expression?

$P_{17}$ : Integral, DI, limit, and sigma notation.

R: So, what do you want to say about equality of $\int_{a}^{b} f(x) d x$ and $\lim _{n \rightarrow \infty} \sum_{i=1}^{n} f\left(x_{i}\right) . \Delta x_{i}$ ?

$P_{17}:$ On one side there is DI, on the other side there are limit and sigma notations, frankly I could not make any connection...

In the post-interview, it has been observed that all participants identified $\int_{a}^{b} f(x) d x=\lim _{n \rightarrow \infty} \sum_{i=1}^{n} f\left(x_{i}\right) . \Delta x_{i}$ expression with RS. P2's response to this question during the interview and his drawings were presented below.

R: What does DI mean?

$P_{2}$ : It means the area under a curve. Riemann sums.

R: Riemann sums, can you explain the sums a little bit more? 
$P_{2}$ : Let's have a curve on the graph. $y=x^{2}$. We divide this region into the pieces. We can divide it into infinite number of rectangular pieces...

R: So, how does it give you this integral, can you explain it a little bit more?

$P_{2}$ : Take the $x_{1}$ point on the $x$-axis, for example, and the $f\left(x_{1}\right)$ point on the y-axis. Let's take the $x_{2}$ point right next to it and take the $f\left(x_{2}\right)$ point on the $y$-axis. Now $x_{2}-x_{1}$ length is the width of the rectangle, which we call $\Delta x$. The length of the other edge of the rectangle will be $f\left(x_{1}\right)$. In this way, if we can find the edge lengths of all the rectangles, we can show them with the sum symbol and we can find the area [P $P_{2}$ writes the whole expression]. And then when we compute limit while $n$ goes to infinity, it gives us DI, a real value.

R: So why are we computing limit?

$P_{2}:$ We actually have two goals. First, we increase the number of partitions by taking $n$ to infinity. And when we increase the number of partitions, we can get closer to the real value. Second, it reduces the difference between the upper sum and the lower sum and is equalized when goes to infinity. Actually, they're the same.

$R:$ So, what does the error mean?

$P_{2}:$ For example, when we divide this area into three pieces, the resulting area and the area when we divide it into five pieces will be different. In fact, we're getting closer to the actual area when we increase the number of partitions.

R: So why does it happen?

$P_{2}$ : Because there are too many gaps. $\left[P_{2}\right.$ shows the area between the rectangles and the graph] (see figure 4 below). The upper sums and lower sums are equalized if we draw infinitely.

$R:$ So, why are we multiplying $f\left(x_{i}\right)$ and $\Delta x_{i}$ ?

$P_{2}$ : Because we found the area of the rectangle, one with a short edge and one with a long edge. The value of this area is actually equal to the expression $\int_{a}^{b} f(x) d x$. That's equal to $F(b)-F(a)$.

$R$ : If there is such an equation [pointing $\int_{a}^{b} f(x) d x=\lim _{n \rightarrow \infty} \sum_{i=1}^{n} f\left(x_{i}\right) . \Delta x_{i}$ to P2] (see figure 4 below), then, is there a relationship between $f(x) d x$ and $f\left(x_{i}\right) \cdot \Delta x_{i}$ ?

$P_{2}:$ Of course, there is. One [pointing the $\left.f\left(x_{i}\right) . \Delta x_{i}\right]$ with a long and short edge of the rectangle and the other $f(x) d x$ is representative. For example, because there is area in this question, these are long and short edges, and if there was a distance on the other side, there would be time and speed. In addition, $\Delta x$ can be very small amounts of edge length, time and so on, and the other one can be the length of long edge, speed and so on... 

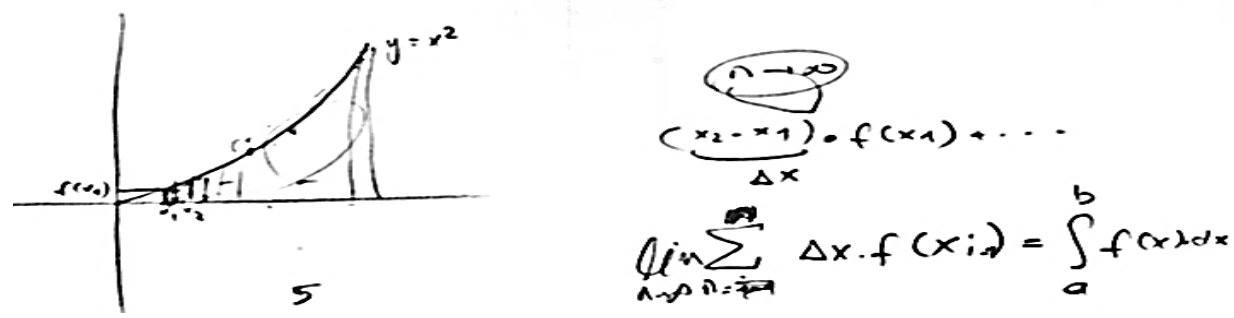

Figure 4. Additional drawing by $\mathrm{P}_{2}$ in the interview

\section{Discussion and Conclusion}

In this study, the TPD was designed according to the emergent modelling approach. During this process, pre-service teachers were engaged in eight modelling activities. The integral test and semi-structured interviews were used to evaluate understanding of DI with the help of RS. Pre-service teachers participated voluntarily in the TPD, and it was seen that they were willing while implementing activities. In the selection of the participants, the researcher's experiences, observations, and opinions about the pre-service teachers were factors. While conducting qualitative research study, the researcher should know the characteristics of the individuals in the study group. In this research, the first author's opinions regarding the characteristics of the pre-service teachers that he spent a long time with made the research strong.

The idea of "partition" was effective in the emergence of integral concept (De Souza, 2012) and it constitutes the basis for RS (Heath, 1912; Thomas \& Finney, 1998). The use of RS for the conceptual understanding of DI is proposed in the literature (Mahir, 2009; Sealey, 2008; Thompson \& Silverman, 2007; Ferrini-Mundi \& Graham, 1984). In the TPD, a hierarchical structure consisting of the development of the idea of partition, the use of RS and the use of DI was designed. In line with the findings of this study, it was concluded that the modelling activities in the TPD were appropriate to the purpose of the study. These findings were consistent with the related literature because engaging students in mathematics and science activities help them understand RS and DI (Jones, 2015b; Sealey, 2014).

The participants usually described representation $\int_{a}^{b} f(x) d x$ as the "area under a curve" or "inverse of derivative" before the TPD in the pre-integral test. The findings of the preinterview supported this situation. The descriptions of the participants as the area under a curve show that they have a limited understanding of the concept of integral (Sealey, 2008). It also supports the view of the "area under a curve" image (Sevimli, 2013) that stands out for DI as a concept image of the participants.

Although the participants have calculated $\int_{a}^{b} e^{x} d x, \int_{a}^{b} e^{\frac{x}{3}} d x$ integrals, they had a difficulty in calculating $\int_{a}^{b} e^{\sqrt{x}} d x, \int_{a}^{b} e^{x^{2}} d x$ integrals. This indicates that integral problems with procedural calculations can be easily solved. Furthermore, only one pre-service teacher could describe DI as a cumulative sum before the TPD. This can be the indicator of the fact that the relationship between DI and RS is not known. This finding is also consistent with the findings of the study conducted by Gonzalez-Martin and Camacho (2004), in which very few students explained RS through the $\int_{a}^{b} f(x) d x$ integral. The fact that the participants could not express cumulative sums before the TPD also shows that their knowledge of RS is not sufficient. 
The area under a curve, inverse of derivative and cumulative sums, was expressed by Girard (2002) and Ostebee and Zorn (1997) to draw attention to the understanding of the integral. At the end of the TPD, the pre-service teachers specified the representation $\int_{a}^{b} f(x) d x$ in at least two categories consisting of area under a curve, the inverse of derivative and cumulative sums. This indicates that the participants' knowledge about DI have changed after the TPD. In addition, at the end of the TPD, most of the participants expressed DI as cumulative sum, the image of which shows the relationship between RS and DI. In this context, the TPD has enabled the pre-service teachers to establish the relationship between RS and DI. This necessitates the use of modelling activities, especially in integral courses in which the traditional method is used.

Establishing the relationship between integral and the concepts of limit and derivative is also important for the understanding of DI. The relationship between DI and derivative concept comes to the fore front at the point of algebraic processes or procedural understanding (Rasslan \& Tall, 2002; Orton, 1983). Before and after the TPD, the participants were able to associate DI with derivative. One of the important differences that emerged after the TPD was the increase in the number of the pre-service teachers who associated DI with FTC. Lack of conceptual image for the concepts of cumulative sums can be the reason for the difficulties experienced in understanding of the FTC (Thompson, 1984). It can be said that the TPD can eliminate this deficiency.

The relationship between DI and limit concept comes to the fore front at the point of understanding RS (Sealey, 2008). Before TPD, it was stated that there was no relationship between DI and limit or that there was an indirect relationship by the participants. This can be further evidence that the relationship between RS and DI has not been established by the participants. At the end of the TPD, the participants were able to explain the existence of the relationship between DI and limit, which indicates that the relationship between DI and RS has been established. This also shows that the understanding of DI has enhanced (Thompson \& Silverman, 2007).

Another indicator for the understanding of DI is the meaning of $\int_{a}^{b} f(x) d x=\lim _{n \rightarrow \infty} \sum_{i=1}^{n} f\left(x_{i}\right) \Delta x_{i}$ equality. This equation also shows the relationship between the symbolic expression of DI $\left(\int_{a}^{b} f(x) d x\right)$ and RS $\left(\lim _{n \rightarrow \infty} \sum_{i=1}^{n} f\left(c_{i}\right) \Delta x_{i}\right)$. These expressions in theoretical structure were understood with the help of the TPD. The next step for the understanding of DI is the use of FTC. The majority of the participants established $\lim _{n \rightarrow \infty} \sum_{i=1}^{n} f\left(c_{i}\right) \Delta x_{i}=\int_{a}^{b} f(x) d x=F(b)-F(a)$ equality by thinking two equalities that are $F(b)-F(a)=\int_{a}^{b} f(x) d x \quad(\mathrm{FTC})$ and $\quad \lim _{n \rightarrow \infty} \sum_{i=1}^{n} f\left(c_{i}\right) \Delta x_{i}=\int_{a}^{b} f(x) d x \quad(\mathrm{RS} \quad$ and $\mathrm{DI})$ together. This equality shows that the possible meanings of DI and the structure of RS were understood together by the participants. This situation reveals that most participants' model of DI shifted towards model for DI, and they reached the relationship between RS, DI and FTC. On the other hand, it may be considered that six-weeks teaching process is not enough for the participants who could not express this equality $\lim _{n \rightarrow \infty} \sum_{i=1}^{n} f\left(c_{i}\right) \Delta x_{i}=\int_{a}^{b} f(x) d x=F(b)-$ $F(a)$. This can be attributed to lack of prior knowledge about function, series (Ergene \& Özdemir, 2020b), limit, derivative or infinity (Çaylan Ergene \& Ergene, 2020; Ergene, 2021b) concepts. 
After the TPD, it was seen that the participants' solutions for $\int_{a}^{b} e^{x^{2}} d x$ changed. The participants drew graph of $\int_{a}^{b} e^{x^{2}} d x$ which cannot be solved algebraically. Moreover, they also used graph even while solving integral problems ( $4^{\text {th }}$ question) which can be solved algebraically. These two situations were important findings that show understanding of integral. In addition, the participants who interpreted $\int_{a}^{b} f(x) d x$ in $5^{\text {th }}$ question as only the area under the curve used RS after the TPD. This situation can be considered as significant for the establishment of the relationship between DI and RS.

\section{Implications}

As a result of the TPD, the participants associated DI with the area under a curve, the inverse of derivative and RS. The idea of partition and the association of DI with RS enhanced their understanding of DI. The use of modelling activities has increased the achievement in integral by enhancing understanding of DI. For this reason, calculus courses can include activities like the modelling activities used in this research. In addition, similar teaching process can be designed to enhance the understanding of other concepts of calculus such as derivative, limit and series.

\section{Acknowledgement}

The manuscript was produced from the doctoral dissertation the first author completed under the supervision of the second author.

\section{References}

Adams, R., \& Essex, C. (2010). Calculus a complete course. Pearson.

Artigue, M. (1991). Analysis, in Advanced Mathematical thinking, edited by D. Tall. Kluwer, Boston, pp. 167-198.

Berry, J. S., \& Nyman, M. A. (2003). Promoting students' graphical understanding of the calculus. The Journal of Mathematical Behavior, 22(4), 479-495. https://doi.org/10.1016/j.jmathb.2003.09.006

Carlson, M. P., Smith, N., \& Persson, J. (2003). Developing and Connecting Calculus Students' Notions of Rate-of Change and Accumulation: The Fundamental Theorem of Calculus. International Group for the Psychology of Mathematics Education, 2, 165-172.

Chapell, K. K., \& Kilpartrick, K. (2003). Effects of concept-based instruction on students' Conceptual understanding and procedural knowledge of calculus. PRIMUS: problems, resources, and issues in mathematics undergraduate studies, 13(1), 17-37. https://doi.org/10.1080/10511970308984043

Chhetri, K., \& Oehrtman, M. (2015). The Equation Has Particles! How Calculus Students Construct Definite Integral Models. In Proceedings of the $18^{\text {th }}$ Annual Conference on Research in Undergraduate Mathematics Education (pp. 19-25).

Cohen, L., Manion, L., \& Morrisson, K. (2000). Research methods in education (5 ${ }^{\text {th }}$ Ed.). Routlenge Falmer.

Creswell, J. W. (2003). Research design: Qualitative, quantitative, and mixed methods approaches ( $2^{\text {nd }}$ ed.). Thousand Oaks, CA: Sage

Çaylan-Ergene, B., \& Ergene, Ö. (2020). Repeating decimals and irrational numbers on the number line: Through the lens of pre-service and in-service mathematics teachers. Acta Didactica Napocensia, 13(2), 215-232. https://doi.org/10.24193/adn.13.2.15 
Darvishzadeh, M., Shahvarani-Semnani, A., Alamolhodaei, H., \& Behzadi, M. (2018). Analysis of student's challenges and performances in solving integral's problems. Journal for Educators, Teachers and Trainers, 9(1), 164 - 177.

De Souza, C. (2012). The Greek method of exhaustion: Leading the way to modern integration. Columbus, Ohio: The Ohio State University.

Doorman, L. M., \& Gravemeijer, K. P. E. (2009). Emergent modeling: discrete graphs to support the understanding of change and velocity. ZDM Mathematics Education, 41(1), 199-211. https://doi.org/10.1007/s11858-008-0130-z

Erbaş, A. K., Çetinkaya, B., Alacacı, C., Çakıroğlu, E., Aydoğan Yenmez, A., Şen et all. (2016). Lise matematik konuları için günlük hayattan modelleme soruları [Real life modelling questions for high school mathematics topics]. Ankara: Türkiye Bilimler Akademisi.

Ergene, Ö. (2014). İntegral hacim problemleri çözüm sürecindeki bireysel ilişkilerin uygulama topluluğu bağlamında incelenmesi. [Investigation of personal relationship in integral volume problems solving process within communities of practices]. Unpublished master dissertation. Marmara University.

Ergene, Ö. (2019). Matematik öğretmeni adaylarının Riemann toplamlarını kullanarak modelleme yoluyla belirli integrali anlama durumlarının incelenmesi. [Investigation of pre-service mathematics teachers' understanding of definite integral through modelling by using Riemann sums]. Unpublished doctoral dissertation. Marmara University.

Ergene, Ö. \& Özdemir, A. Ş. (2020a). Investigating pre-service elementary mathematics teachers' perception of integral. Marmara University Atatürk Education Faculty Journal of Educational Sciences, 51(51), 155-176. https://doi.org/10.15285/maruaebd.622149

Ergene, Ö, \& Özdemir. A. Ş. (2020b). A study on the pre-service elementary mathematics teachers' knowledge on the convergence and divergence of series in the context of theoretical and application. Revista Latinoamericana de Investigación en Matemática Educativa, 23(2), 203-232. https://doi.org/10.12802/relime.20.2323

Ergene, Ö. (2021a). Integral kavramına yönelik kayg1, tutum ve kullanışlılık düzeylerinin incelenmesi [Examination of anxiety, attitude and usefulness levels regarding the concept of integral]. Journal of Research in Education and Teaching, 10(3), 1-18.

Ergene, Ö. (2021b). Öğretmen Adayları Gözünden Sonsuzluk Kavramı ve Matematik Dersi Öğretim Programı [The Concept of Infinity and Mathematics Lesson Curriculum from the Perspectives of Pre-service Teachers]. Journal of Van Yüzüncü Yll University Faculty of Education, 18(2), 123-151. https://doi.org/10.33711/yyuefd.998263

Ferrini-Mundi, J., \& Graham, K. (1994) Research in calculus learning: Understanding of limits, derivatives and integrals. In J. J. Kaput \& E. Dubinsky (eds.), Research Issues in Undergraduate Mathematics Learning, MAA (Notes 33, pp.31-45). Washington DC: MAA.

Girard, N. R. (2002). Students' representational approaches to solving calculus problems: Examining the role of graphing calculators. Unpublished EdD, Pittsburg: Universityof Pittsburg.

González-Martín, A. S., \& Camacho, M. (2004). What is first-year Mathematics students' actual knowledge about improper integrals?. International Journal of Mathematical Education in Science and Technology, 35(1), 73-89. https://doi.org/10.1080/00207390310001615615

Gravemeijer, K. (1999). How emergent models may foster the constitution of formal mathematics. Mathematical thinking and learning, 1(2), 155-177. https://doi.org/10.1207/s15327833mt10102_4 
Gravemeijer, K. (2007). Emergent modeling as precursor to mathematical modelling. In W. Blum, P. Galbraith, W. Henn ve M. Niss Modelling and applications in mathematics education. The $14^{\text {th }}$ ICMI Study (pp. 137-144). New York: NY: Springer.

Gravemeijer, K., \& Stephan, M. (2002). Emergent models as an instructional design heuristic. In K. Gravemeijer, R. Lehrer, B. Oers ve L. Verschaffel, Symbolizing, modeling and tool use in mathematics education (pp. 145-169). Kluwer Academic Publishers.

Heath, T. (1912). The method of Archimedes. Cambridge University Press.

Jones, S. R. (2015a). Areas, anti-derivatives, and adding up pieces: Definite integrals in pure mathematics and applied science contexts. The Journal of Mathematical Behavior. 38, 9-28. https://doi.org/10.1016/j.jmathb.2015.01.001

Jones, S. R. (2015b). The prevalence of area-under-a-curve and anti-derivative conceptions over Riemann-sum based conceptions in students' explanations of definite integrals. International Journal of Mathematics Education in Science and Technology, 46(5), 721-736. https://doi.org/10.1080/0020739X.2014.1001454

Jones, S. R. (2018). Prototype images in mathematics education: The case of the graphical representation of the definite integral. Educational Studies in Mathematics, 97(3), 215-234. https://doi.org/10.1007/s10649-017-9794-z

Jones, S. R., Lim, Y., \& Chandler, K. R. (2017). Teaching integration: How certain instructional moves may undermine the potential conceptual value of the Riemann sum and the Riemann integral. International Journal of Science and Mathematics Education, 15(6), 1075-1095. https://doi.org/10.1007/s10763-016-9731-0

Knuth, E. J. (2002). Secondary school mathematics teachers' conceptions of proof. Journal for research in mathematics education, 33(5), 379-405. https://doi.org/10.2307/4149959

Koçak, Ş., \& Erdoğan, N. K. (2013). Matematik II [Mathematics II]. Anadolu Üniversitesi.

Mahir N. (2009). Conceptual and procedural performance of undergraduate students in integration, International Journal of Mathematical Education in Science and Technology. 40(2), 201-211. https://doi.org/10.1080/00207390802213591

McDermott, L. E., Rosenquist, M.L., \& van Zee, E. H. (1987). Student difficulties in connecting graphs and physics: Examples from kinematics. American Journal of Physics. 55. 503-513. https://doi.org/10.1119/1.15104

Meredith, D. C., \& Marrongelle, K. A. (2008). How students use mathematical resources in an electrostatics context. American Journal of Physics, 76(6), 570-578. https://doi.org/10.1119/1.2839558

Nguyen, D. H., \& Rebello, N. S. (2011). Students' understanding and application of the area under the curve concept in physics problems. Physical Review Special Topics- Physics Education Research. 7, 010112.

Orton, A. (1983). Students' understanding of differentiation. Educational Studies in Mathematics, 14(3), 235-250.

Orton, A. (1984). Understanding rate of change. Mathematics in School, 13(5), 23-26.

Ostebee, A., \& Zorn, P. (1997). Calculus from graphical, numerical and symbolic points of view. Fort Worth, TX: Saunder College Publishing.

Rasslan, S., \& Tall, D. (2002). Definitions and images for the definite integral concept. In Cockburn A.; Nardi, E. (eds.) Proceedings of the 26th PME, 4, 89-96.

Sealey, V. (2008). Calculus students' assimilation of the Riemann integral into a previously established limit structure. Unpublished doctoral dissertation, Arizona: Arizona State University.

Sealey, V. (2014). A framework for characterizing student understanding of Riemann sums and definite integrals. The Journal of Mathematical Behavior, 33(1), 230-245. https://doi.org/10.1016/j.jmathb.2013.12.002 
Serhan, D. (2015). Students' understanding of the definite integral concept. International Journal of Research in Education and Science, 1(1), 84-88.

Sevimli, E. (2013). Bilgisayar cebiri sistemi destekli ögretimin farklı düşünme yapısındaki ögrencilerin integral konusundaki temsil dönüşüm süreçlerine etkisi [The effect of a computer algebra system supported teaching on processes of representational transition in integral topics of students with different types of thinking] Unpublished doctoral dissertation. Marmara University.

Shekutkovski, N. (2013). Definition of the definite integral. The Teaching of Mathematics, 16(1), 1, 29-34.

Simmons, C., \& Oehrtman, M. (2017). Beyond the product structure for definite integrals Proceedings of the $20^{\text {th }}$ special interest group of the Mathematical Association of America on research in undergraduate mathematics education. SIGMAA on RUME.

Stein, S.K., \& Barcellos, A. (1992) Calculus and Analytic Geometry. $5^{\text {th }}$ Edition, McGrawHill, Inc.

Thomas, G., \& Finney, R. (1998). Calculus and analytic geometry ( $9^{\text {th }}$ Edition). AddisonWesley Publishing Company.

Thomas, G. B., Weir, M. D., Hass, J., \& Giordano, F. R. (2016). Thomas' calculus (13 ${ }^{\text {th }}$ ed.). Pearson Education, Addison-Wesley.

Thompson, P. W. (1994). The development of the concept of speed and its relationship to concepts of rate. In G. Harel, \& J. Confrey. The development of multiplicative reasoning in the learning of mathematics (pp. 181-234). Albany: NY: SUNY Press

Thompson, P. W., \& Silverman, J. (2007). The Concept of accumulation in calculus. In M. Carlson and C. Rasmussen (Eds.), Making the connection: Research and Teaching in Undergraduate Mathematics (pp. 117-131).

Wagner, J. F. (2018). Students' obstacles to using Riemann sum interpretations of the definite integral. International Journal of Research in Undergraduate Mathematics Education, 4(3), 327-356. https://doi.org/10.1007/s40753-017-0060-7

Yin, R. (2003). Case study research: Design and methods ( $3^{\text {th }}$ edition). Thousand Oaks, Sage Publications. 


\section{Appendix}

\section{Teaching Process of Definite Integral (TPD)}

TPD was designed for the first author's doctoral dissertation. Literature review, expert opinions and researcher experiences were effective in the design process. Activities in TPD were based on the Development of Disintegrating Idea, Using Riemann Sums and Using Definite Integral. Activities, their purposes and references are presented below.

\begin{tabular}{|c|c|c|}
\hline Activities & Purpose & References \\
\hline$A_{1}$ : Motorized Courier & Development of Disintegrating Idea & (Thompson, 1984) \\
\hline $\mathrm{A}_{2}:$ Karasu Coast & Disintegrating Idea and Introduction to RS & (Koçak \& Erdoğan, 2013) \\
\hline $\mathrm{A}_{3}$ : A Broken Odometer & Using RS and Introduction DI & (Stein \& Barcellos, 1996) \\
\hline $\mathrm{A}_{4}$ : Non-Uniform Rope & Using RS Sums and Introduction DI & (Stein \& Barcellos, 1996) \\
\hline $\mathrm{A}_{5}$ : Marking & Using DI & (Erbas et al., 2016) \\
\hline $\mathrm{A}_{6}:$ Ivriz Dam & Using DI & (Sealey, 2008) \\
\hline $\begin{array}{l}\text { Evaluation I: Student } \\
\text { Service }\end{array}$ & Evaluation of $A_{1}-A_{2}-A_{5}$ & Designed by the researchers \\
\hline $\begin{array}{l}\text { Evaluation II: Chain on } \\
\text { the Roof }\end{array}$ & Evaluation of $\mathrm{A}_{3}-\mathrm{A}_{4}-\mathrm{A}_{6}$ & (Adams \& Essex, 2003) \\
\hline
\end{tabular}

For the validity of the designed modelling activities expert opinions were taken and for the reliability of the designed modelling activities a pilot study was conducted. Modelling activities were analyzed by using the Riemann Integral Framework (Sealey, 2008). The modelling activities in TPD were designed according to the emergent modelling approach (Gravemeijer, 1999).

Since TPD is a part of a doctoral dissertation, it does not seem possible to include whole process in the article. For this reason, in this research the effect of TPD on the understanding of Definite Integral was given by providing some information about TPD. Readers who want to get detailed information about TPD can contact to the responsible author. In this section, some of the modelling activities used in the TPD were given with brief information.

\section{Areas of Shapes}
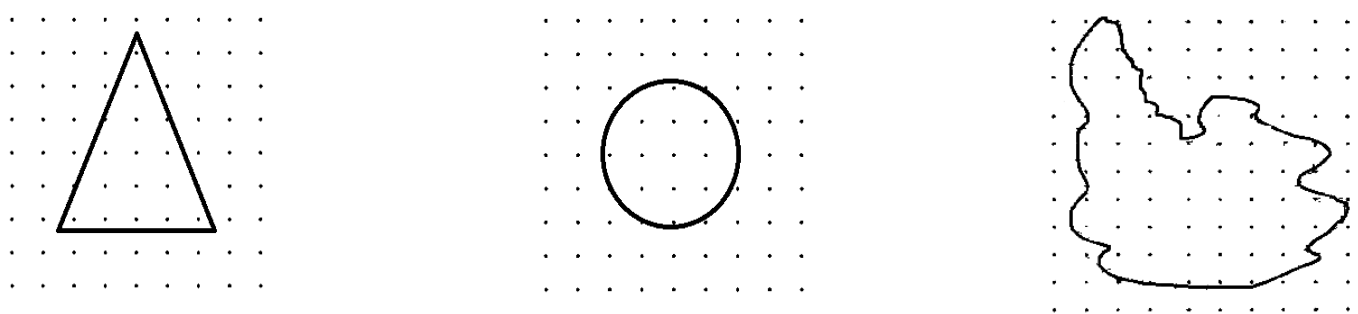

Calculate the area of the shapes given above.

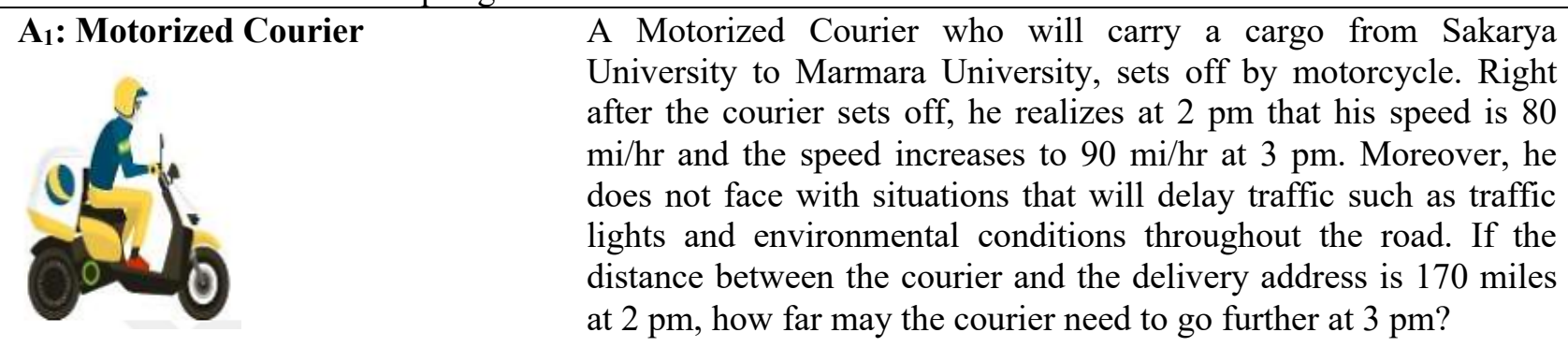

After $\mathrm{H}_{1}$ and $\mathrm{A}_{1}$, the researcher tried to convey disintegration idea by using questioning and brainstorming 
methods.

Then, $\mathrm{H}_{2}$ was given to the pre-service teachers as a homework.

\section{Homework: $\mathrm{H}_{1}$ : Area Under a Curve}

For the graph of a function $y=x^{2}$, find the area of the region bounded by $x$-axis, $x=0$ and $x=2$ in Region I.

\section{$\mathrm{A}_{2}$ : Karasu Coast}

For greening Works, Sakarya Metropolitan Municipality wants to turn a certain area between the river and the road into green on the Karasu Coast. The shortest and longest distances between the road and the river were represented in meters. As it is known that $18 \mathrm{TL}$ will be paid for the grass to be planted per square meter of green area, how much will the required grass cost for the project be?

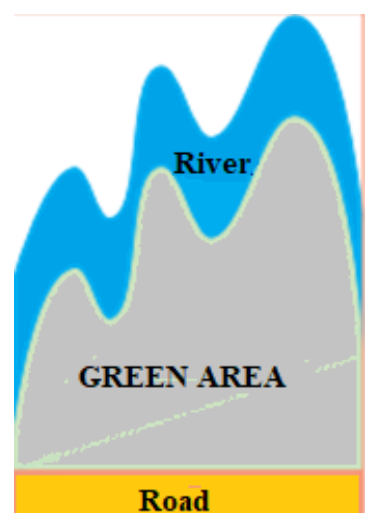

\begin{tabular}{lll} 
& $\begin{array}{l}\text { Shortest } \\
\text { Distance to } \\
\text { Road }\end{array}$ & $\begin{array}{l}\text { Longest } \\
\text { Distance to } \\
\text { Road }\end{array}$ \\
\hline $\mathbf{1}$ & 0 & 18 \\
\hline $\mathbf{2}$ & 16 & 20 \\
\hline $\mathbf{3}$ & 15 & 27 \\
\hline $\mathbf{4}$ & 26 & 30 \\
\hline $\mathbf{5}$ & 23 & 28 \\
\hline $\mathbf{6}$ & 24 & 33 \\
\hline $\mathbf{7}$ & 33 & 35 \\
\hline $\mathbf{8}$ & 12 & 33 \\
\hline
\end{tabular}

\section{A4: Non-Uniform Rope}
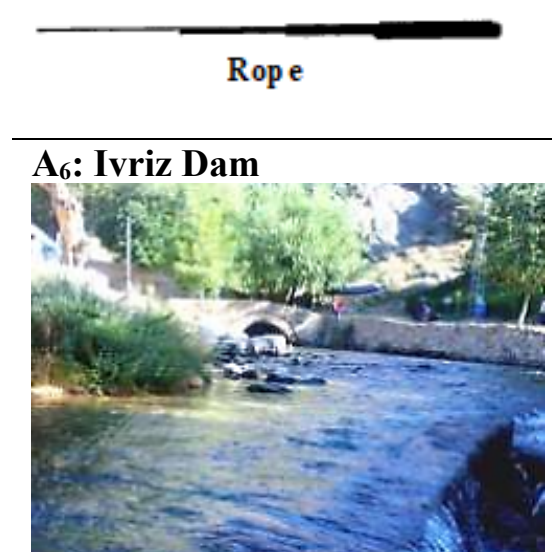

A thin rope with a length of $3 \mathrm{~cm}$ is very light at one end and gradually gets heavier towards the other end. In reality, its density is $x^{2}$ grams per $\mathrm{cm}$ at a distance of $x \mathrm{~cm}$ from its light end. Calculate the approximate weight of the rope as shown in the figure below.

A uniform pressure $\mathrm{P}$ applied across a surface area A creates a total force of $F=P A$. The density of water is $1,003 \mathrm{~kg}$ per cubic meter, so that under water the pressure varies according to depth, $\mathrm{d}$, as $P=$ $1,003 d$. Find the total force exerted on a dam that is 1000 meter wide and extends 30 meter underwater. 